\section{The double hit}

\section{Sharif Islam BDS debates 'the oft- overlooked inequity beleaguering the bedrocks of dental practice, our dental nurses'.}

Labels. Pouches. Log book. Hurry! Hurry! Everything has to be bagged and tagged, and then stamped with a date and then entered into the book, and then audited to make sure it had the right date on it, and then audited again to make sure it got into the book in the first place. No time to sit around and smell the disinfectant, your dentist needs more instruments, and the teeth need charting and notes need taking and coffee needs making; well, ok, that last one is optional.

It's not easy, is it? Even at the best of times the workload of a dental nurse can pile up and block the view in front. But now with all the extra regulation raining down upon us from the CQC, that pile is fast becoming a mountain whose ascending shadow has radical implications for the way everyone in practice works. That old nursing handbook that proved a faithful ally in your daily struggle now has to be ripped up and rewritten for a modern age. An age where a labyrinth of rules and regulations, measurements and mandates coalesce into a dense forest that obscures the job you thought you signed up for.

Now, of course, there may be some merits to this added burden. All facets of dental practice may become more refined and better structured, resulting in a professional service to our patients that is beyond reproach. But, just as likely, it is for the interests of government too, now able to record every measurement to help bolster its record come Election Day. The salient issue to be salvaged from between the colliding timbers of this imposition is one of fairness, especially towards the dental nurse; a balance that yearns to be forged between the benefits to the practice as a whole and the ability of the dental nurse to perform their job with unchallenged enthusiasm and efficiency.

The reality is that dental nurses are spending an increasing amount of their valuable time chasing these endless targets, eating into the time required of their essential surgery duties. Dentists are becoming increasingly frustrated with the absence of their assistants from the surgery, who, through no fault of their own, have been dragooned by the call of sterilisation pouches and wall charts. Having the proverbial cake and eating it too inevitably means longer appointment times, and longer intervals between them. While no suggestion of rush is intended, this undoubtedly impacts on productivity, allowing fewer patients to be seen in the available time while the dental nurse busily attends to his or her additional duties.

Unfortunately, fairness is seemingly a distant consideration for the dental nurse. Not only are his or her extortionate taxes paying to fund all the additional bureaucracy, but also nothing by way of financial incentive or compensation is provided for him or her in lieu of the additional workload. Draconian directives that compel a dental nurse to stay late with their dentist do not come with any such compulsion to pay him or her extra for the trouble. Thus, $\mathrm{s} / \mathrm{he}$ is paying for the privilege of being weighed down, and then gets hit again when it costs him or her in unpaid time. A double hit.

A simple answer may be to increase the salaries of dental nurses in view of their increased workload. But principals may argue that this is unfair on them too, as they did not seek to impose these burdens in the first place. Furthermore, the dentists themselves are potentially at a loss from these new regulations, having to pay for the additional infrastructure to meet the requirements. So, we reach an impasse between dental nurses who have every reason to take umbrage at an unfair levy, practices that do not feel obliged to compensate them, and a government that is pillaging the spoils of everyone's labour to bring about this scenario in the first place.

Some might argue that these are grounds enough to unionise and take action.

However, most dental nurses are paid in the private sector, where competition and the markets determine rates of pay, rather than the government. Action against practices themselves would also prove futile, as they could simply hire new personnel at the same rate, although this type of overhaul would itself be an unrealistic and cumbersome process. Dental nurses could simply be told that the job now entails this extra workload, and they are no more exempt from it than the dentists are from theirs.

We are thus left to debate an oftoverlooked inequity beleaguering the bedrocks of dental practice, our dental nurses. It is an indefensible oversight by the CQC to require so much of this essential profession, without whom practice would cease to function, and yet deny any provision to reward them. It places principals in a difficult position, to ask more of their staff for no visible return. And it engenders despondency amongst the dental nurses themselves, who may come to resent their job instead of cherish it. The only certainty is that all dental professionals will have to pull together in the spirit of teamwork to make this evolution successful; after all, what alternative do we have?

What do you think? Email vitaleditorial@ nature.com.

\section{Worth every penny}

In response to the letter A no-win situation in the spring issue of Vital magazine (page 4) regarding my article Let your hygienist shine (Vital autumn 2011 pages 24-26), I think the author of this letter missed the point of the article slightly. Her [or his] response is somewhat indicative if the current state of affairs in our profession. To say that her patients cannot find value in perio treatment scares me somewhat, and saying that only the affluent can afford perio treatment is unfair and untrue. I have several patients that are not 'affluent' and have had to save up for treatment, but they would rather do that than visit an NHS practice or indeed another private practice in my local area. If my patients could not see any 'worth' in my treatment they wouldn't a) complete treatment and b) recommend their friends and family members to our practice. I'm sure if my patient in the article were questioned he would tell you it was worth all of the $£ 586$ he paid for treatment.

Gemma Langford RDH

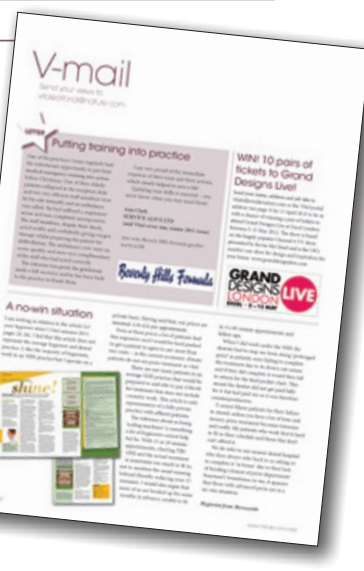

